\title{
MRM needs more information resources
}

\author{
Graham Jarvis \\ is the former editor of the Chartered Institute of Marketing's Technology Group Newsletter. He will be the editor of its \\ rebranded version. He is also an analyst for Bloor Research, and researches and writes marketing technology white papers \\ and articles for information communications technology companies like GOSS, FIRM and ICDL.
}

It is very hard to find any independent articles or other types of information sources of significance on the internet about marketing resource management (MRM). I wonder whether this is a part of the malaise that acronyms foster. There are a number of terms out there, used by even the most experienced marketers, that at the end of the day fall down to the elementary, basic principles of marketing. As with many other acronyms, there isn't always a clear definition that tells a layman exactly what MRM really is.

I would argue that MRM is therefore swamped - and not sufficiently recognised - and that it is seen as part of the wider marketing picture. The management of resources is a crucial function in any company. MRM at least recognises the need to use these resources effectively and efficiently, with the customer at the forefront of strategic planning. MRM should also facilitate a connection with sales strategy and force marketers and salespeople to work together and to communicate more regularly and effectively.

Like it or not, people are a resource. They are the engine of any company; the fuel of any business is, of course, money. Technology plays a role too, and it is one that can alter the culture of an organisation, but it shouldn't be implemented just for the sake of it. This was often one of the problems facing customer relationship management (CRM) implementations, the other being that rather than making the customer king, it made the customer the serf of the company he or she bought or sold goods and services from.

David Hood, CIMTech's Chair, has often argued that customers don't want a relationship with any organisation anyway, unless they choose to. He also believes that MRM is part of managing total marketing (MTM), which has some similarities with MRM. MTM focusses on taking a holistic approach to profit-making, with the customer controlling the relationship, the manner in which he or she would like to be communicated with and other forms of interaction.

Customer managed relationships are far more intuitive and they stick to marketing basics to the extent that, with regards to MTM, the resources of the entire company, rather than one department, are driven towards the goal: making money by increasing throughput (sales) and reducing inventory and operating expenses through economies of scale and not simply because you need to cut costs for the sake of it. 
At the end of the day, anything that you do is connected to a critical chain. This can either help you to deliver customer expectations and increase your return on investment, or it could lead to failure and many lost opportunities for making more profit. This may also mean that people cannot always be segmented in a database, you cannot believe that everyone living in one street, according to socio-demographics, will buy the same products.

CRM databases are not bad though, particularly if they are used in the right way (which applies to any type of technology). There must be a well-focussed business case and an appropriate, customer-centric long-term strategic plan in place for any such implementation to be successful. Yet, in the absence of decent independent information, except from the MRM vendors, how do you find out more about MRM? In particular, how does technology fit into its paradigm?

\section{TIME TO CREATE THE MRM LIBRARY}

All is not lost, however. The Chartered Institute of Marketing's Technology Group (CIMTech) newsletter (http://www.cimtech.org/newsletter) covers a wide range of marketing-related topics, including MRM. In fact the group has an MRM spokesperson, the insightful Freddie Daniells, CEO of Cogentum (http://www.cogentum.com). $\mathrm{He}$ is widely respected within the MRM space for his in-depth knowledge, advice and foresight. He can help you to find the right MRM technology vendor for your own company, maximise the use of your existing marketing resources and take you through any change management processes.

Some of his articles on MRM can also be found on MarketingProfs (www.marketingprofs.com). He also write his own blog on MRM, which you should be able to access through his website. Another recently published report 'Cogentum: Take 3 Steps to Business Success' takes a look at MRM. The first step looks at the needs of your organisation, then how technology can add value to your marketing department and the final stage looks at adoption.

The recent MOM-MRM Symposium organised by Henry Stewart Conferences, is also a good source of information about marketing operations management and MRM. Not only is it a good place to find out more about the vendors (eg Aprimo and Freedman International) and MRM itself, it is also is a very good forum for debating the issues. Hood, for example, gave a presentation about MTM's at the London event and Daniells — who argues that MTM is very much akin to MRM - spoke at both the London and New York events.

The MRM explained website, http://www.mrm-explained.com/ is another source of information about MRM, MOM and digital asset management (DAM). It recommends www.gistics.com, which provides a free guide to preparing your business for MRM and includes some useful advice covering best practice and procedures. MRM Explained believes that GISTICS should 'take the panic out of the process of selecting MRM'.

If you need some independent research, then you should have a look at http://www.marketinggovernance.com/, which 'collects together papers from suppliers, consultants and users. The site is very useful and often thought provoking,' MRM Explained comments. A list of suppliers and further information can also be found in Table 1 .

A web search reveals a number of other meanings for MRM, which to a 
Table 1: Suppliers of and sources of information about marketing relationship management (MRM)

\begin{tabular}{ll}
\hline MRM Explained Supplier Guide & (http://www.mrm-explained.com/MRM/ \\
& suppliers.htm\#suppliers); \\
Margo Rosenberg Marketing & An independent consultancy, which provides help with \\
(http://www.mrm-marketing.co.uk/) & marketing strategy and planning for companies within the \\
& IT sector. \\
Pelagon & as above \\
(http://www.pelagon.co.uk/solutions/mrm.htm) & \\
Scottish Enterprise & http://www.scottish-enterprise.com/mrm \\
E-consultancy.com & has some features on MRM. \\
\hline
\end{tabular}

degree is buried amongst non-marketing-related topics. There also appears to be no book available on the subject, which may be because the term 'marketing resource management' is still considered to be quite new, even if some of the concepts aren't. I must emphasise that companies looking to implement an
MRM, or even a CRM, solution should look outwards-in at the customer before inwards-out in advance of deciding which solution is best suited to increase marketing effectiveness while managing marketing efficiencies.

(C) Graham Jarvis 